\title{
Proactive effects in pigeons' timing behavior: Implications for an internal-clock model
}

\author{
DONALD M. WILKIE \\ University of British Columbia, Vancouver, British Columbia, Canada
}

\begin{abstract}
We have found proactive effects in pigeons' timing behavior, a finding inconsistent with internalclock models of timing that assume a resetable working-memory component. Six pigeons were trained to discriminate between 2- and 10-sec illuminations of a white light; choice of a red pecking key was correct and rewarded after presentation of the short stimulus whereas choice of a green key was correct and rewarded after presentation of the long stimulus. During training sessions, there were 60 trials separated by a 20 -sec intertrial interval; short and long light occurred in a randomized order and correct choices were reinforced with 5-sec access to grain on a partial (75\%) schedule. During test sessions, there were 120 trials separated by a 2-sec intertrial interval. Light presentations occurred in a fixed order throughout these sessions: $2,6,10,10,6,2$, $2,6,10 \mathrm{sec}$, and so forth. Choice of either red or green after $6 \mathrm{sec}$ was not reinforced. However, red continued to be correct after $2 \mathrm{sec}$ and green continued to be correct after $10 \mathrm{sec}$. Of central interest was how the subjects classified $6 \mathrm{sec}$ of light in ascending $(2,6,10)$ and descending $(10$, $6,2)$ sequences of durations: Subjects chose the short alternative on $42 \%$ of the 6 -sec trials in ascending series but only $29 \%$ in descending series, a result most plausibly interpreted as showing that duration information from a preceding trial affects duration classifications on the current trial. Such proactive effects should not occur according to working-memory models that assume that stored information is cleared at the end of a trial.
\end{abstract}

It has been amply demonstrated that animals such as rats and pigeons can discriminate the duration of events. In a typical laboratory study using pigeons, for example, a light in a Skinner box is turned on for either 2 or $10 \mathrm{sec}$ and followed immediately by the presentation of red and green pecking keys; pecking red is correct and rewarded after the 2-sec stimulus, whereas pecking green is correct and rewarded after the 10 -sec stimulus. Pigeons quickly learn to choose the appropriate color, and in addition respond to intermediate durations between 2 and $10 \mathrm{sec}$ in a graded fashion, choosing red ("short") progressively less often for durations of 4,6 , and $8 \mathrm{sec}$.

An information-processing approach to duration discriminations proposed by Church and his colleagues (e.g., Church, 1984) has received considerable support. One information-processing model, depicted in Figure 1, comprises five components: (1) a pacemaker that emits a stream of pulses; (2) a gate (switch) that is opened at the onset of the event to be timed and closed at its offset; (3) a counter that accumulates pulses; (4) two memories-a permanent ("reference") memory, which stores the total number of pulses of rewarded durations and a temporary ("working") memory, which stores the number of pulses accumulated on a particular trial, and (5) a comparator that compares the values stored in the two memories. If,

This research was supported by the Natural Sciences and Engineering Research Council of Canada. Shayne Kardel assisted with the experiments. Rob Willson and two anonymous reviewers provided valuable comments. Requests for reprints may be sent to Donald $M$. Wilkie, Department of Psychology, University of British Columbia, 2136 West Mall, Vancouver, BC V6T 1Y7, Canada.
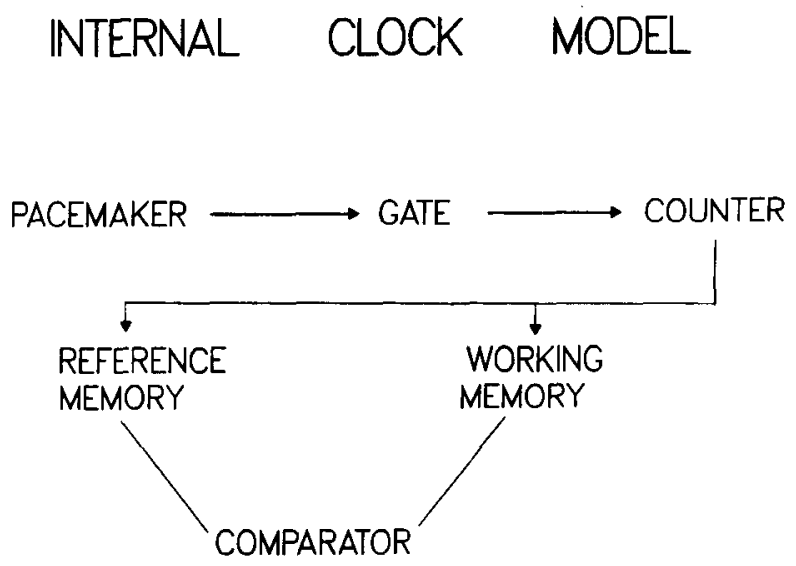

Figure 1. Schematic of internal-clock model of animals' ability to discriminate durations of events.

after event presentation, the value stored in working memory is similar to the short value stored in reference memory, a "short" choice is made; if the value stored in working memory is similar to the long value stored in reference memory, a "long" choice is made.

A common assumption made about working memory is that it, like the temporary memory in the common electronic calculator, is dichotomous: either information is in storage or it is cleared. It is generally assumed that the working memory is cleared as soon as the information stored in it is no longer useful-typically at the end of a trial (Honig, 1978; Olton, 1978). Consequently, according to this view, there should be no proactive interfer- 
ence between trials. In terms of an internal-clock model containing a resetable working memory, classification of a stimulus as short or long on Trial $n$ should not be affected by the duration of the sample on Trial $n-1$. The present study was undertaken to see if this was the case.

Because proactive effects sometimes are not observed except at very short intertrial intervals (Grant, 1975), we used a short (2-sec) intertrial interval. In the test for proactive effects, we gave pigeons ascending $(2-, 6-$, and $10-$ sec-sample) and descending (10-, 6-, and 2-sec-sample) sequences of trials. Of key interest was how the subjects classified the 6-sec stimulus. In the absence of proactive effects, the 6-sec sample should be classified in the same way in ascending and descending sequences. That is, if the subjects choose the short alternative on $40 \%$ of the 6-sec trials in 2-6-10 sequences, they should choose short on a similar percentage on 10-6-2 sequences. On the other hand, if proactive effects were to occur, these percentages might differ. Specifically, if duration information from Trial $n-1$ was retained to Trial $n$, subjects might be more likely to classify a 6-sec stimulus as long in a 10-6-2 sequence than in a 2-6-10 sequence.

\section{EXPERIMENT 1}

\section{Method}

\section{Subjects}

Six King pigeons, maintained at about $90 \%$ of normal body weight, served as subjects. The pigeons were housed individually in large plastic-coated mesh cages with free access to water as well as health grit and oyster shells. The colony was maintained on a light-dark cycle matched with natural sunrise and sunset times; the subjects were tested 5 days a week, about 1 to $3 \mathrm{~h}$ after colony light onset.

\begin{abstract}
Apparatus
Each pigeon was tested consistently in one of six test chambers containing a houselight, grain feeder, and two pecking keys, which could be lit with red or green light. A Data General NOVA 3 computer and MANX state notation software (Gilbert \& Rice, 1979) controlled the experimental equipment and collected the responses.
\end{abstract}

\section{Procedure}

Pretraining. Since each pigeon had had recent event-duration training ( 5 subjects had served in the Wilkie, 1987, study; the 6th subject also had been previously trained to discriminate 2 and $10 \mathrm{sec}$ of light), no preliminary training was needed. Each subject first received about 1 month of training identical to that described for the training sessions below.

Experiment proper. The experiment lasted 28 days and comprised seven 2-day blocks of both training and test conditions. Training sessions consisted of 60 trials, separated by a $20-\mathrm{sec}$ intertrial interval spent in darkness. Two- and 10-sec sample trials occurred in a randomized order with an equal probability. Immediately after the light presentation, two pecking keys were lit, one with red and one with green light, with the right-left location of the colors varied randomly over trials. For some pigeons, red was designated as correct and was rewarded after the short stimulus; for others, green was correct. (For convenience in exposition, we assume that red is always correct after the short stimulus.) Choice of the correct key produced 5-sec access to mixed grain on a partial (75\%) reinforcement schedule.
Test sessions comprised 120 trials separated by a 2 -sec intertrial interval, again spent in darkness. Light presentations occurred in a fixed order throughout these sessions: $2,6,10,10,6,2,2,6$, $10 \mathrm{sec}$, and so forth. Choice of either red or green after the 6-sec sample was not reinforced. However, red continued to be correct after $2 \mathrm{sec}$, and green, correct after $10 \mathrm{sec}$. On all correct trials, the grain hopper was raised for $1 \mathrm{sec}$; on a random one-half of these trials, it remained raised for an additional $4 \mathrm{sec}$.

In each session, a record was kept of the number of times the "short" choice key was selected when 2-, 6-, and 10-sec lights were presented. A separate record was kept for 6-sec samples preceded by 2 - and 10 -sec samples on the previous trial. These values were cumulated over sessions and used to calculate the percentage of trials on which the pigeons chose the "short" alternative after durations of 2, 6 (preceded by a 2 -sec sample), 6 (preceded by a 10 -sec sample), and $10 \mathrm{sec}$ of the light.

\section{Results}

As shown in Figure 2, the percentage of trials on which the pigeons chose the short alternative during test sessions differed when $6 \mathrm{sec}$ of light was preceded on the previous trial by a 2- or 10-sec sample. Specifically, the pigeons chose short more frequently on 6-sec trials preceded by 2 -sec samples than on 6-sec trials preceded by 10 -sec samples.

This observation was confirmed in a two-factor (four trial types, blocks of sessions) repeated measures analysis of variance. The main effect of trial type was highly significant $[F(3,20)=80.4, p<.001]$. Post hoc tests (Newman-Keuls, $p<$. 05) showed that performance on the 6-sec trials preceded by 2 -sec samples was different from performance on 6-sec trials preceded by 10-sec samples, and that both of these types of trials differed from the simple 2- and 10-sec trials. Performance on 2- and $10-\mathrm{sec}$ trials also differed significantly.

The interaction of trial type and blocks of sessions was also significant $[F(18,85)=2.38, p=.004]$ due to the

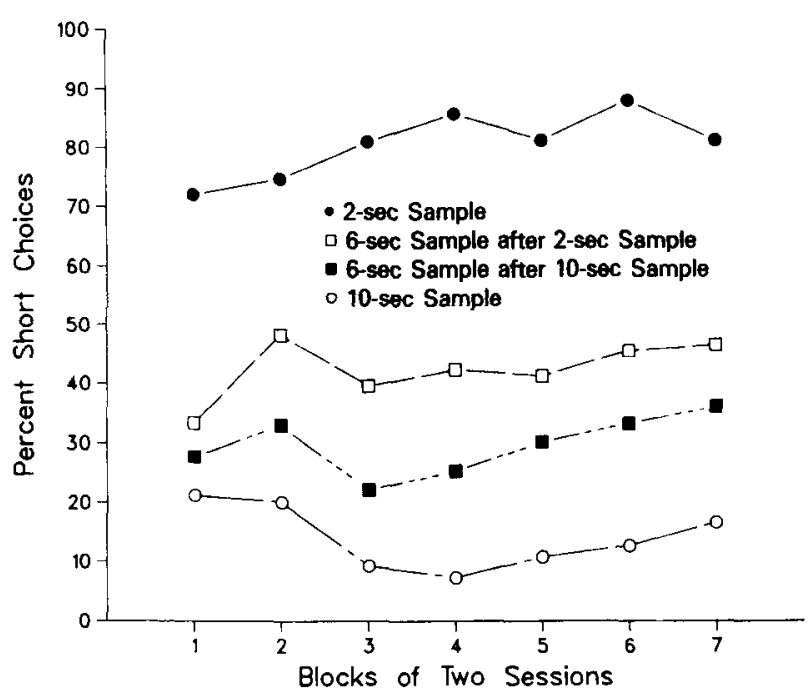

Figure 2. Percent of trials on which the pigeons chose the "short" alternative when the light sample was $2(\circ)$ or 10 sec $(\circ)$, or was 6 sec preceded by a 2- (ㅁ) or 10-sec (I) sample on the previous trial. 
tendency of the subjects to become more accurate on 2and 10-sec trials after the first two blocks of sessions.

The proportion of short choices on 6-sec trials in both the ascending series $(42.28 \%)$ and descending series (29.48\%) were significantly less than $50 \%[t(5)=-6.56$, $p=.0012$ and $t(5)=-10.02, p=.0002$, respectively], a result consistent with a subjective middle somewhat less than the arithmetic mean.

\section{Discussion}

The results suggest that duration information from an earlier trial is carried forward to a succeeding trial where it affects classification of event duration on that trial. The obvious implication of this finding is that working memory is not cleared as soon as its contents are of no further use. However, before discarding the idea of a resetable working-memory component in internal-clock models, we thought it was important to rule out an alternative explanation for the proactive effect we had found.

It is possible that working memory is cleared at trial end and that proactive effects arise from subjects' remembering (and repeating) the choice made on a previous trial. That is, pigeons might not remember the duration of light from Trial $n-1$ on Trial $n$ but might, rather, remember responding "short" (red) or "long" (green). By this view, proactive effects result from interference among response decisions and not in the content of working memory. There is some empirical support for such a notion. Roberts (1980), for example, in a matching-tosample study, found that pigeons were more accurate on Trial $n$, when the correct choice on Trial $n$ was the same choice made on Trial $n-1$, regardless of whether that choice was correct and rewarded. For example, pigeons were more accurate on Trial $n$ involving a horizontal line sample when they had responded incorrectly (to horizontal) on Trial $n-1$ which had a vertical sample than when they had responded correctly to the vertical choice. Similarly, they were less accurate on a horizontal Trial $n$ when they had responded correctly to vertical on Trial $n-1$. Church (1980) reported similar results for rats in a duration-discrimination experiment.

To determine if our pigeons had momentarily perseverated in their choices across trials, we carried out two control experiments.

\section{CONTROL EXPERIMENT 1}

In this experiment we switched subjects trained to choose red after a short sample and green after a long sample to a red-green matching-to-sample task. Response perseveration should result in greater-than-chance matching levels, even during the first few trials of color matching.

\section{Method}

Subjects and Apparatus

The subjects and apparatus were the same as previously described.

\section{Procedure}

The subjects received 10 sessions identical to the training sessions described above. They then received three red-green matching sessions. Red or green samples were presented on either of the two keys. The samples remained on until pecked, at which time they were turned off and the feeder was raised for $3 \mathrm{sec}$. Then both red and green were presented with positions randomized over trials. Choice of the matching color was rewarded with 5-sec access to grain. The sessions comprised 60 trials separated by a 15 -sec intertrial interval.

\section{Results and Discussion}

The subjects showed no evidence of matching at greaterthan-chance levels. Across the three sessions, accuracy scores for the 6 pigeons were: $46.5 \%, 44.8 \%, 52.4 \%$, $42.6 \%, 49.6 \%$, and $44.8 \%$. [The one-sample $t$ test against a mean of $50 \%$ was $t(5)=-2.19, p=.08$.] Responding to red or green (during sample presentation) does not produce any tendency to repeat this response a few seconds later (during the choice phase of the matching trial).

\section{CONTROL EXPERIMENT 2}

Another way to determine whether memory for which response was made rather than for which sample was presented is responsible for the effect seen in Figure 2 is to analyze choice on 6-sec trials as a function of whether the subject was correct or incorrect on the preceding 2or $10-\mathrm{sec}$ trial. If pigeons choose incorrectly on the preceding trial because they have forgotten the sample, and if the difference on 10-6 and 2-6 trials is due to the carryover of memory of the sample from the preceding trial, there should be no difference on 6-sec trials preceded by $10-$ or 2 -sec trials. That is, the difference on 10-6 and 2-6 trials should occur only when the subjects are correct on the 10- and 2-sec trials. If the difference on 10-6 and 2-6 trials arises because of the carryover of the response made on the preceding trial rather than the carryover of memory, then the difference between 10-6 and 2-6 trials should be reversed when subjects make errors on 2- and 10-sec trials.

Method
Subjects and Apparatus
The subjects and apparatus were the same as previously described.
Procedure
The subjects received 32 sessions, of which 16 were test sessions
and 16 training sessions identical to those described in Experiment 1 .
The trials in test sessions were also identical to the test trials in
Experiment 1, except that more detailed data collection was im-
plemented. Choices on 6-sec trials were recorded as a function of
whether a subject was correct or incorrect on the preceding 2- or
10-sec trials.

\section{Results and Discussion}

Figure 3 shows the percentage of 6-sec sample trials on which the subjects chose the short alternative as a function of whether the 6-sec trial was preceded by a correct 


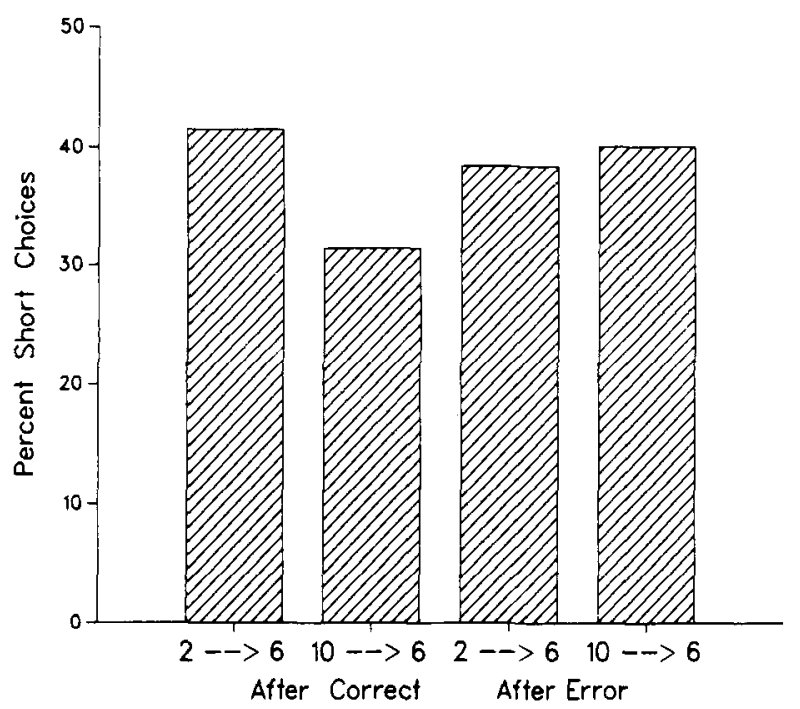

Figure 3. Percent of trials on which the pigeons chose the "short" alternative when the 6-sec sample was preceded by 2 - and 10-sec trials on which choices were correct or incorrect.

or incorrect choice on a 2- or 10-sec trial. When the subjects were correct on the trial preceding the 6-sec trial, they again chose the short alternative more frequently when the preceding trial was $2 \mathrm{sec}$ than when it was $10 \mathrm{sec}$, replicating the main result of Experiment 1 . When an error was made on the trial preceding the 6-sec trial, the subjects were about equally likely to choose short after a 10-sec sample as after a 2-sec sample. The difference in choosing short after 2- and 10-sec samples following an error was not significant $[t(5)=-.17, p=$ .87]. After a correct choice, the difference was highly significant $[t(5)=4.14, p=.009]$.

These results, like those of the first control experiment, suggest that subjects' choices on the 6-sec trial are influenced by the sample duration on the preceding trial rather than on the response made on that trial. Had the subjects simply remembered the response made on the preceding trial, they should have chosen short more often on 6-sec trials preceded by 10-sec trials on which an error was made; this clearly did not occur. Rather, the subjects chose short about equally often on 6-sec trials following an error. This is exactly the pattern expected when subjects forget the duration of the sample on the 2- or 10-sec sample trial.

\section{GENERAL DISCUSSION}

Although proactive effects are common in studies on animal short-term memory (see, e.g., the review by Wright, Urcuioli, \& Sands, 1986), not all are inconsistent with a resetable working-memory process. Proactive interference produced by intratrial manipulations (e.g., presenting a red then a green sample and asking the subject to remember green) are actually predicted by workingmemory models that assume that information is cleared at the end of a trial (cf. Wilkie, 1986). However, proac- tive effects produced by intertrial manipulations such as those used here are clearly incompatible with the notion of a resetable working memory.

It seems clear that our view of the working-memory component of the internal-clock model of pigeons' timing behavior must be revamped. In considering how this might be done, it is important to keep in mind the fact that proactive interference probably is not a major factor in timing with conventional intertrial intervals of about $20 \mathrm{sec}$. What this implies is that information remains in working memory for a limited time past the end of a trial. One might argue that the resetting operation is delayed past the end of the trial, but this solution is totally ad hoc. A better solution might be to abandon the idea of a resetting/clearing operation in favor of a passive decay process. There is some theoretical justification for this suggestion-a decay-like process for temporal information has been previously proposed in two other contexts. Staddon and Dale (see Staddon, 1983) have proposed a dual-code model to account for animals' spatial memory in tasks such as the radialarm maze. Briefly, it is assumed in this model that animals encode two types of information-spatial and temporalin the form of a place-time code. Whenever a spatial cue occurs, the temporal code associated with this place is reset to maximum value; the code then decays in a hyperbolic fashion over time. According to this model, animals use the strength of the temporal code in deciding whether or not to enter an arm: Arms with strong temporal codes are avoided. Even more relevant is the "subjective shortening" model proposed by Spetch and Wilkie $(1982,1983)$. In several duration-discrimination studies, we noticed that when a retention interval was imposed between the short or long event and the red and green choice stimuli, the pigeons tended to choose the short alternative, and that this "choose short" effect increased as the length of the retention interval increased. To account for this effect, we proposed that the pigeons' subjective representation of event duration in working memory becomes systematically shortened during the retention interval. Consequently, after long retention periods, the remembered duration of the long event is more similar to the actual duration of the short event. This shortening process, rather than representing some distortion of memory may actually be the way in which working memory is normally cleared. That is, the remembered duration of an event might be foreshortened with the passage of time, both during a lengthy retention interval and during the intertrial interval. If this view is correct, the remaining challenge will be to specify the mechanism by which event duration representation in working memory is shortened.

\section{REFERENCES}

Church, R. M. (1980). Short-term memory for time intervals. Learning \& Motivation, 11, 208-219.

Church, R. M. (1984). Properties of the internal clock. In J. Gibbon \& L. Allan (Eds.), Annals of the New York Academy of Sciences: Timing and time perception (Vol. 423, pp. 566-582). New York: New York Academy of Sciences. 
GILBERT, S. G., \& RicE, D. C. (1979). NOVA SKED II: A behavioral notation language utilizing the Data General Corporation real-time operating system. Behavior Reseanch Methods \& Instrumentation, 11, 71-73.

GRANT, P. S. (1975). Proactive interference in pigeon short-term memory. Joumal of Experimental Psychology: Animal Behavior Processes, 1, 207-220.

HoNIG, W. K. (1978). Studies of working memory in the pigeon. In S. H. Hulse, H. Fowler, \& W. K. Honig (Eds.), Cognitive processes in animal behavior (pp. 211-248). Hillsdale, NJ: Erlbaum.

OLton, D. S. (1978). Characteristics of spatial memory. In S. H. Hulse, H. Fowler, \& W. K. Honig (Eds.), Cognitive processes in animal behavior (pp. 341-373). Hillsdale, NJ: Erlbaum.

ROBERTS, W. A. (1980). Distribution of trials and intertrial retention in delayed matching to sample with pigeons. Joumal of Experimental Psychology: Animal Behavior Processes, 6, 217-237.

SPETCH, M. L., \& WILKIE, D. M. (1982). A systematic bias in pigeons' memory for food and light duration. Behaviour Analysis Letters, 2 , 267-274.
SPETCH, M. L., \& WILKIE, D. M. (1983). Subjective shortening: A model of pigeons' memory for event duration. Journal of Experimental Psychology: Animal Behavior Processes, 9, 14-30.

STADDON, J. E. R. (1983). Adaptive behavior and leaming. Cambridge: Cambridge University Press.

WILKIE, D. M. (1986). Pigeons' spatial memory: V. Proactive interference in the delayed matching of key location paradigm occurs only under restricted conditions. Animal Leaming \& Behavior, 14, 257-266.

WILKIE, D. M. (1987). Stimulus intensity affects pigeons' timing behavior: Implications for an internal clock model. Animal Leaming \& Behavior, 15, 35-39.

Wright, A. A., Urculou, P. J., \& SANDS, S. F. (1986). Proactive interference in animal memory. In D. F. Kendrick, M. E. Rilling, \& M. R. Denny (Eds.), Theories of animal memory (pp. 101-125). Hillsdale, NJ: Erlbaum.

(Manuscript received August 4, 1987;

revision accepted for publication November $23,1987$. 